\title{
Study Subject Medical Imaging
}

National Cancer Institute

\section{Source}

National Cancer Institute. Study Subject Medical Imaging. NCI Thesaurus. Code C115523.

Medical imaging of a study participant as part of a clinical trial. 